\title{
Co-infections in COVID-19 critically ill and antibiotic management: a prospective cohort analysis
}

\author{
Alexia Verroken ${ }^{1 *}$ (D) Anaïs Scohy ${ }^{1}$, Ludovic Gérard ${ }^{2}$, Xavier Wittebole ${ }^{2}$, Christine Collienne ${ }^{2}$ \\ and Pierre-François Laterre ${ }^{2}$
}

International guidelines recommend the initiation of empirical antibiotherapy for possible associated bacterial pneumonia in COVID-19 critically ill yet further suggesting a rapid reassessment upon source documentation [1]. In this prospective cohort analysis, we investigated the respiratory co-infection rate in COVID19 critically ill through the use of rapid molecular testing and measured its impact on antibiotic management.

This preliminary analysis was conducted over a 1month period at the intensive care unit (ICU) of the Cliniques universitaires Saint-Luc and included all COVID-19 adult patients from whom a lower respiratory tract sample could be obtained. Specimens were conveyed to the microbiology laboratory where a FilmArray Pneumonia Panel plus test (FA-PNEU, BioFire Diagnostics, Salt Lake City, UT, USA) was performed. The FA-PNEU is an automated multiplex PCR test allowing direct detection of 15 bacteria with a semiquantitative value, 3 atypical bacteria, 9 viruses, and 7 antimicrobial resistance genes within $1 \mathrm{~h}$ and $15 \mathrm{~min}$ [2]. FA-PNEU testing was done $24 / 7$, and results were immediately called to the intensive care physician pursuing antimicrobial optimization.

Forty-one COVID-19 patients were admitted to ICU, and 32 could be included upon respiratory sample availability. The study population was comparable to previously described COVID-19 critically ill in terms of age, sex ratio, severity scores, comorbidities, and symptoms [3]. FA-PNEU was performed within a mean of 10 days following symptoms' onset and a mean of 1 day

\footnotetext{
* Correspondence: alexia.verroken@uclouvain.be

${ }^{1}$ Department of Microbiology, Cliniques Universitaires Saint-Luc - Université Catholique de Louvain, Avenue Hippocrate 10, Brussels, Belgium

Full list of author information is available at the end of the article
}

following ICU admission. FA-PNEU results identified $13 / 32(40.6 \%)$ patients with a bacterial co-infection as detailed in Table 1. Staphylococcus aureus, Haemophilus influenza, and Moraxella catarrhalis were the principal bacteria identified with significant genome copies. None of the 32 FA-PNEU tests identified atypical bacteria neither other respiratory viruses. Direct communication of FA-PNEU results led to speeded-up antibiotic modifications in $15 / 32(46.9 \%)$ patients.

It is a known difficulty to adjudicate on the presence of a co-infection in COVID-19 patients particularly in critically ill. Clinical presentation, inflammatory markers, and bilateral radiological infiltrates lead to misperception and cannot be used in the diagnosis of a bacterial superinfection. As a consequence, empirical antibiotherapy is quasi-systematically initiated until microbiological documentation of co-infecting pathogens. Yet, current data on co-infections is limited. With the focus on intensive care settings, a case series in February 2020 analyzing 21 COVID-19 ICU patients reported no bacterial respiratory co-infections but 3 influenza infections [4]. A similar case series investigated in March 2020 stated none of the 15 COVID-19 critically ill had a bacterial coinfection neither were they tested positive for respiratory viruses [5]. No information however was available on how patients were tested neither on treatment strategy. In our setting applying generalized molecular screening for co-infection, the rate was $40.6 \%$ and the main detected pathogens were causal agents of communityacquired pneumonia.

As rapid molecular testing was performed within the shortest possible time following ICU admission, a majority of our patients did not receive empirical antibiotherapy while awaiting FA-PNEU result. Ultimately one 
Table 1 FA-PNEU results and antibiotic management (this table should appear after the result section)

\begin{tabular}{|c|c|c|c|c|}
\hline \multirow{2}{*}{$\begin{array}{l}\text { Patient } \\
\text { no. }\end{array}$} & \multirow{2}{*}{$\begin{array}{l}\text { Sample } \\
\text { type }\end{array}$} & \multirow{2}{*}{$\begin{array}{l}\text { FA-PNEU results } \\
\text { Detected pathogens }\left(10^{6} \geq 10^{7}\right)\end{array}$} & \multicolumn{2}{|c|}{ Treatment switch initiated by FA-PNEU results } \\
\hline & & & Initial antibiotherapy & $\overline{\text { Subsequent antibiotherapy }}$ \\
\hline 1 & Sputum & - & None & None \\
\hline 2 & ETA & Pseudomonas aeruginosa & None & Ceftazidime \\
\hline 3 & ETA & Moraxella catarrhalis & None & Cefuroxime \\
\hline 4 & ETA & - & None & None \\
\hline 5 & ETA & - & None & None \\
\hline 6 & Sputum & - & None & None \\
\hline 7 & ETA & - & None & None \\
\hline 8 & ETA & - & Cefuroxime & None \\
\hline 9 & Sputum & Haemophilus influenza & None & Cefuroxime \\
\hline 10 & ETA & - & None & None \\
\hline 11 & ETA & - & Cefuroxime & None \\
\hline 12 & ETA & M. catarrhalis & Cefuroxime & Cefuroxime \\
\hline 13 & ETA & Staphylococcus aureus & None & Flucloxacilline \\
\hline 14 & ETA & - & None & None \\
\hline 15 & ETA & - & None & None \\
\hline 16 & ETA & Streptococcus agalactiae & Cefuroxime & Cefuroxime \\
\hline 17 & Sputum & - & None & None \\
\hline 18 & ETA & S. aureus & None & Flucloxacilline \\
\hline 19 & ETA & - & Cefuroxime & None \\
\hline 20 & ETA & - & None & None \\
\hline 21 & ETA & S. aureus & Amoxicilline - clavulanic acid & Amoxicilline - clavulanic acid \\
\hline 22 & Sputum & H. influenza & None & Cefuroxime \\
\hline 23 & ETA & H. influenza & None & Cefuroxime \\
\hline 24 & ETA & - & Cefuroxime & None \\
\hline 25 & ETA & S. aureus & Cefuroxime & Flucloxacilline \\
\hline 26 & ETA & - & None & None \\
\hline 27 & Sputum & S. aureus + mecA/C & None & Vancomycine \\
\hline 28 & Sputum & - & None & None \\
\hline 29 & Sputum & - & None & None \\
\hline 30 & Sputum & - & Piperacilline-tazobactam & None \\
\hline 31 & ETA & - & None & None \\
\hline 32 & ETA & S. aureus + mecAVC $-H$. influenza & None & Vancomycine + cefuroxime \\
\hline
\end{tabular}

ETA endotracheal aspirate, FA-PNEU FilmArray Pneumonia Panel plus test

third of the patients remained antibiotic-free over the entire process, and 5 patients had their antibiotics stopped following a negative FA-PNEU result. These antibiotic savings are crucial for COVID-19 critically ill known to have a long ICU stay with reported nosocomial infection rates as high as $31 \%$ [6].

To conclude, bacterial documentation is essential to assess co-infection in COVID-19 critically ill. The use of molecular diagnostic tools and the initiation of narrowspectrum antibiotics are key elements of COVID-19 antimicrobial stewardship guidelines in critically ill.
Studies on larger populations and in different geographical areas should be performed to outline analogous antibiotic saving strategies.

\section{Abbreviations}

ICU: Intensive care unit; FA-PNEU: FilmArray Pneumonia Panel plus test

\section{Acknowledgements}

We thank all interns from the intensive care units for their collaboration in the inclusion of the critically ill. We also thank all laboratory technicians and interns from the clinical laboratory who performed the testing. Ultimately, we thank all patients and their family that participated in this study. 


\section{Authors' contributions}

$A V$ and PFL designed the study. LG, XW, CC, and PFL included the patients. $A V$ and AS collected and summarized the clinical data. AV and PFL drafted the manuscript. AS, $L G, X W$, and $C C$ revised the final manuscript. The authors read and approved the final manuscript.

\section{Funding}

This work was funded by the BioFire Diagnostics (Salt Lake City, UT, USA) as they supplied 2 FilmArray systems and the tests. The Biofire Diagnostics did not have any role in the design of the study neither in the collection, analysis, and interpretation of data.

\section{Availability of data and materials}

The datasets used and analyzed during the current study are available from the corresponding author on reasonable request.

\section{Ethics approval and consent to participate}

The study was approved by the Hospital-Faculty Ethics Committee Saint-Luc - UCL (National number: B403). The patient or his family signed an informed consent prior to inclusion.

\section{Consent for publication}

Not applicable

\section{Competing interests}

The authors declare that they have no competing interests.

\section{Author details}

'Department of Microbiology, Cliniques Universitaires Saint-Luc - Universite Catholique de Louvain, Avenue Hippocrate 10, Brussels, Belgium. Intensive Care Department, Cliniques Universitaires Saint-Luc - Université Catholique de Louvain, Avenue Hippocrate 10, Brussels, Belgium.

Received: 10 June 2020 Accepted: 1 July 2020

Published online: 09 July 2020

\section{References}

1. Poston JT, Patel BK, Davis AM. Management of critically ill adults with COVID-19. JAMA. 2020. https://doi.org/10:1001/jama.2020.4914.

2. Weber DM, Wallace MA, Burnham CAD, Anderson NW. Evaluation of the BioFire FilmArray Pneumonia panel for detection of viral and bacterial pathogens in lower respiratory tract specimens in the setting of a tertiary care academic center. J Clin Microbiol. 2020. https://doi.org/10.1128/JCM. 00343-20.

3. Yang X, Yu Y, Xu J, Shu H, Xia J, Liu H, Wu Y, Zhang L, Yu Z, Fang M, Yu T, Wang Y, Pan S, Zou X, Yuan S, Shang Y. Clinical course and outcomes of critically ill patients with SARS-CoV-2 pneumonia in Wuhan, China: a singlecentered, retrospective, observational study. Lancet Respir Med. 2020. https://doi.org/10.1016/S2213-2600(20)30079-5.

4. Arentz M, Yim E, Klaff L, Lokhandwala S, Riedo FX, Chong M, Lee M. Characteristics and outcomes of 21 critically ill patients with COVID-19 in Washington State. JAMA. 2020. https://doi.org/10.1001/jama.2020.4326.

5. Bhatraju PK, Ghassemieh BJ, Nichols M, Kim R, Jerome KR, Nalla AK, Greninger AL, Pipavath S, Wurfel MM, Evans L, Kritek PM, West TE, Luks A, Gerbino A, Dale CR, Goldman LD, O'Mahony S, Mikacenic C. Covid-19 in critically III patients in the Seattle Region - case series. N Engl J Med. 2020. https://doi.org/10.1056/NEJMoa2004500.

6. Huang C, Wang Y, Li X, Ren L, Zhao J, Hu Y, Zhang L, Fan G, Xu J, Gu X, Cheng Z, Yu T, Xia J, Wei Y, Wu W, Xie X, Yin W, Li H, Liu M, Xiao Y, Gao H, Guo L, Xie J, Wang G, Jiang R, Gao Z, Jin Q, Wang J, Cao B. Clinical features of patients infected with 2019 novel coronavirus in Wuhan, China. Lancet. 2020; https://doi.org/10.1016/50140-6736(20)30183-5.

\section{Publisher's Note}

Springer Nature remains neutral with regard to jurisdictional claims in published maps and institutional affiliations. 